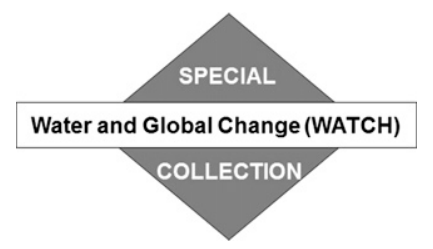

\title{
WATCH: Current Knowledge of the Terrestrial Global Water Cycle
}

\author{
Richard Harding, ${ }^{*}$ Martin Best, ${ }^{+}$Eleanor Blyth, ${ }^{*}$ Stefan Hagemann, ${ }^{\text {Pavel Kabat, }}{ }^{@}$ \\ LENA M. TALlAKSEN, ${ }^{\&}$ TANYA WARNAARS, ${ }^{*}$ DAVID WibERG, ${ }^{*} *$ GRAHAM P. WEEDON, ${ }^{+}$ \\ HENNY VAN LANEN, ${ }^{++}$FULCO LUDWIG, ${ }^{@}$ AND INGJERD HADDELAND ${ }^{@, \# \#}$ \\ * Centre for Ecology and Hydrology, Wallingford, United Kingdom \\ ${ }^{+}$Met Office Hadley Centre, Wallingford, United Kingdom \\ \# Max Planck Institute for Meteorology, Hamburg, Germany \\ @ Earth System Science and Climate Change Group, Wageningen University, Netherlands \\ \& Department of Geosciences, University of Oslo, Norway \\ ** International Institute for Applied Systems Analysis, Laxenburg, Austria \\ ${ }^{++}$Hydrology and Quantitative Water Management Group, Centre for Water and Climate, Wageningen University, \\ Netherlands \\ \#\# Norwegian Water Resources and Energy Directorate, Oslo, Norway
}

(Manuscript received 24 February 2011, in final form 16 June 2011)

\begin{abstract}
Water-related impacts are among the most important consequences of increasing greenhouse gas concentrations. Changes in the global water cycle will also impact the carbon and nutrient cycles and vegetation patterns. There is already some evidence of increasing severity of floods and droughts and increasing water scarcity linked to increasing greenhouse gases. So far, however, the most important impacts on water resources are the direct interventions by humans, such as dams, water extractions, and river channel modifications. The Water and Global Change (WATCH) project is a major international initiative to bring together climate and water scientists to better understand the current and future water cycle. This paper summarizes the underlying motivation for the WATCH project and the major results from a series of papers published or soon to be published in the Journal of Hydrometeorology WATCH special collection. At its core is the Water Model Intercomparison Project (WaterMIP), which brings together a wide range of global hydrological and land surface models run with consistent driving data. It is clear that we still have considerable uncertainties in the future climate drivers and in how the river systems will respond to these changes. There is a grand challenge to the hydrological and climate communities to both reduce these uncertainties and communicate them to a wider society.
\end{abstract}

\section{Introduction: Drivers of environmental change}

The global water cycle is an integral part of the Earth system. It plays a central role in our climate, controlling the global energy cycle as well as carbon, nutrient, and sediment cycles. Increasing temperature, associated with increasing $\mathrm{CO}_{2}$ concentrations, will increase ocean evaporation, leading to increased atmospheric humidity, modest increases in rainfall, and larger increases in heavy rainfall (Held and Soden 2006; Bates et al. 2008). There is already evidence that rainfall, runoff, and evaporation have increased, and will continue to do so (Wentz et al.

Corresponding author address: Dr. Richard Harding, Centre for Ecology and Hydrology, Maclean Building, Benson Lane, Wallingford OX10 8BB, United Kingdom.

E-mail: rjh@ceh.ac.uk
2007; Huntington 2006). However, rising $\mathrm{CO}_{2}$ concentrations may also reduce evaporation because of stomatal closing under elevated $\mathrm{CO}_{2}$ concentrations. Superimposed on the effects of climate change will be the other impacts of human activities, such as land cover change and exploitation of water resources. In the short term at least, these latter influences will have an equal or even greater impact on water resources.

Globally, freshwater resources far exceed human requirements. However, by the end of the twenty-first century these requirements will begin to approach total available water. Regionally, water demands-for agriculture and domestic/industrial use-already exceed supply (Vörösmarty et al. 2000). This is likely to be exacerbated with increasing population and society's changing water demands, a situation exacerbated by the need to maintain river flows for ecosystem and human 
services (Bates et al. 2008; Strzepek and Boehlert 2010; Ward et al. 2010; Vörösmarty et al. 2010). As a result, in many regions water (particularly groundwater) is being exploited in an unsustainable way, leading to long-term declines in groundwater levels (McGuire 2009; Rodell et al. 2009).

Strong interactions between the climate, hydrology, and land use occur (Claussen 2004; Falloon and Betts 2010). The snow-climate feedback is well known and described (e.g., Cess et al. 1991). However, feedbacks between $\mathrm{CO}_{2}$, vegetation, soil moisture, groundwater recharge, and climate are less well understood and are not well described in most climate and hydrological models. Over $18 \%$ of total cultivated land is irrigated (Fischer et al. 2007); additionally, much nonagricultural land has been substantially modified by human activities. Conversion of land to agriculture not only impacts the local evaporation and hydrological response, but may also influence the distribution of rainfall and evaporative demand in the surrounding landscape (see Lucas-Picher et al. 2011, this collection). Agriculture and urban development have increased substantially in the past century and will continue to develop in the twenty-first century. Therefore, any assessment of the world's water resources must take into account both the direct and indirect influences of land use changes and the exploitation of the riverine system. The Water and Global Change (WATCH) special collection of papers summarize recent advances in our understanding of the global water cycle, building on work of other projects such as the Global Water System Project (http://www.gwsp.org).

\section{Observed changes of the hydrological regime}

There are at least seven global land gridded datasets for rainfall (Trenberth et al. 2007; Biemans et al. 2009), and each varies in the methodology with which the gauge data has been interpolated in the application of gauge corrections (especially for snowfall) and in the use of satellite data. At the global scale the precipitation datasets do differ in their totals, although their interannual variability and trends are largely similar. The mean annual land precipitation estimates vary from 96286 to $118006 \mathrm{~km}^{3} \mathrm{yr}^{-1}\left(743-926 \mathrm{~mm} \mathrm{yr}^{-1}\right)$ for the years 1979 99 (Biemans et al. 2009). The overall trend is an increase in the early part of twentieth century, a decrease between 1950 and 1990, and an increase since then. Regionally, there have been decreases in the Northern Hemisphere tropics (West and East Africa and southern Asia) with distinct upward trends at high latitudes. Zhang et al. (2007) conclude that anthropogenic forcing has contributed significantly to these observed zonal changes in precipitation. There is some evidence for the increased intensity of precipitation in Europe (Klein Tank and Konnen 2003; Zolina et al. 2010) and worldwide (Groisman et al. 2005). The increase in heavy rainfall is more than the percentage average and is consistent with climate model simulations in an increasing $\mathrm{CO}_{2}$ environment (Allen and Ingram 2002; Wentz et al. 2007). Similarly, the occurrence of rainfall droughts appears to have increased in the last five decades (Dai et al. 2004; Burke et al. 2006).

Evaporation responds to a number of different drivers. Higher temperatures will lead to higher evaporative demand, but increasing $\mathrm{CO}_{2}$ concentrations may cause stomatal closure, leading to reduced evaporation (Gedney et al. 2006). However, both these influences may lead to enhanced vegetation growth (and hence leaf area), enhancing further evaporation (Gerten and Gedney 2008). Long-term trends have been noted from the pan evaporation datasets (Roderick et al. 2007; Roderick and Farquhar 2002), which have been ascribed to changes in aerosols causing changes in incoming solar radiation (Wild et al. 2005). Jung et al. (2010) show, from an analysis of the direct measurements from the Flux Network (FLUXNET) and models, that evaporation increased from 1982 to 1997 (ascribed to a reduction in aerosols) with a leveling off in recent years-perhaps the result of soil moisture limitations.

River discharge is susceptible to a large number of influences, including changes in climate, land cover, and land and water management. For this reason it is difficult to ascribe observed changes in river discharge to changes in climate. In fact, most observed changes will be a direct consequence of human activities (such as extractions, dams, and regulations). Döll et al. (2009) show, through an analysis of modeled river flow, that the seasonal flow amplitude has significantly decreased on one-sixth of global land as a result of water withdrawals and dams. Overall runoff has increased, particularly in the highlatitude basins, which are less influenced by water withdrawals (Peterson et al. 2002). During the second part of the twentieth century and the beginning of the twentyfirst century (1950-2008), river runoff has decreased over most of Africa, southern Europe, South and East Asia, eastern Australia, Central America, the central Pacific coasts of North America, and some parts of South America, which is broadly consistent with patterns of precipitation (Dai 2010). In a study of comparatively undisturbed small catchments across Europe, Stahl et al. (2010) show a regionally coherent picture of decreasing annual streamflow in southern and eastern Europe over the period 1962-2004 and generally positive trends elsewhere (especially in the north). Evidence from the observed dataset further reveals that low flows have decreased in most regions with a summer minimum and that a marked shift toward drier conditions is observed 


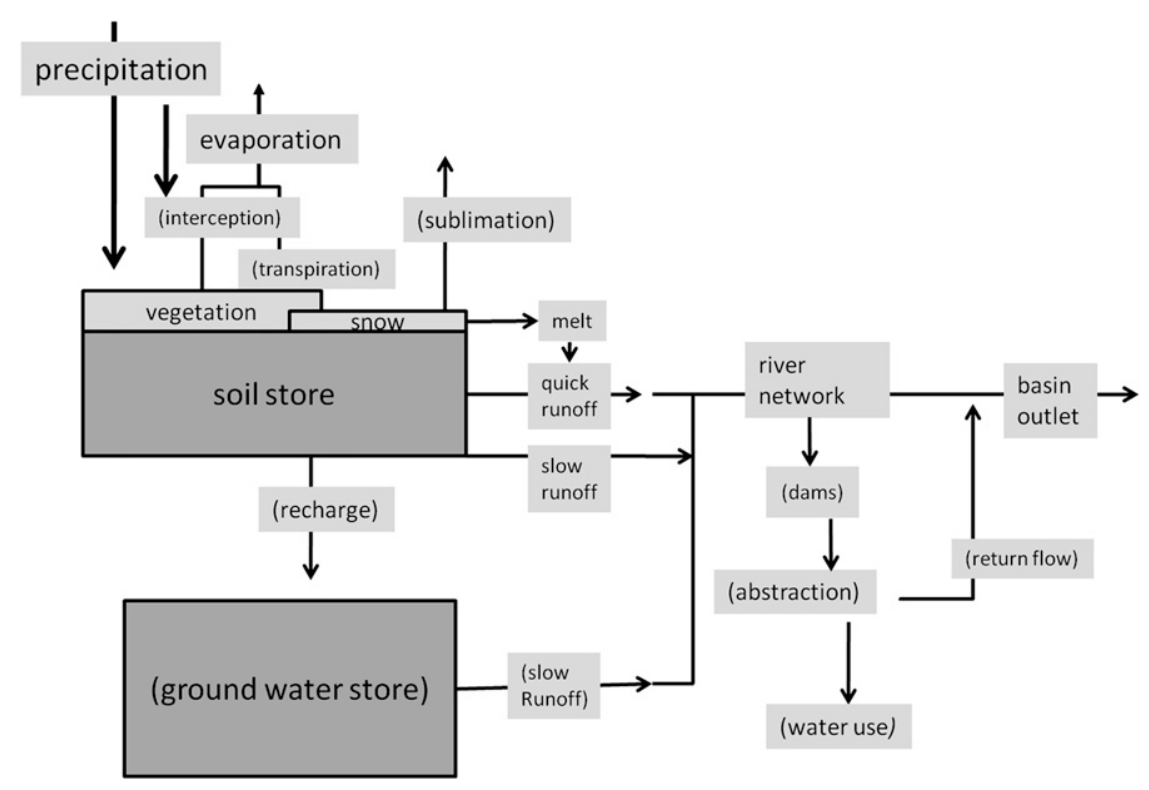

FIG. 1. Generic representation of large-scale hydrological models; processes in brackets are not represented in all models.

to be widespread across Europe in spring and summer months. Pall et al. (2011) has been able to demonstrate that the major floods in the United Kingdom in 2000 were made more likely by the increase in $\mathrm{CO}_{2}$ concentrations. In general, the large-scale patterns of change in recent decades agree with the hydrological responses as projected by climate models for the twentieth century.

\section{Hydrology models and meteorological driving data}

There is a great diversity of hydrological models and approaches, ranging from conceptually based lumped models (e.g., Jakeman and Hornberger 1993) to distributed physically based hydrological models (e.g., Abbott et al. 1986). This range has developed in response to many different requirements in terms of scale, purpose, and availability of data (including catchment characteristics and available forcing and calibration data). Models to predict future water resources should be as physically based as possible (Fig. 1). In practice, though, it has proved difficult to construct entirely physically based models capable of simulating runoff patterns over a wide range of time and space scales without recourse to calibration (e.g., Beven 2002).

Models describing components of the global water cycle can be grouped into

- land surface hydrology models (LSMs),

- global hydrological models (GHMs), and

- river basin hydrological models (RBHMs).
LSMs have their origins in the land surface descriptions within climate models. Generally these are based on the energy balance at the land surface and describe the vertical exchanges of heat, water, and, sometimes, carbon very well. More recently they have incorporated representations of lateral transfers of water (Blyth 2001), typically using semidistributed model concepts such as those found in TOPMODEL (Beven 2001), the Probability Distributed Model (PDM; Moore 2007), or the Variable Infiltration Capacity (VIC) model (Liang et al. 1994). RBHMs close the water balance at the basin scale and have a good representation of lateral transfers, but are weak in the representation of energy balance components and carbon linkages. They also frequently require basin-specific, often optimized, parameters. However, these models have proved extremely useful in studies of climate impacts in specific basins (e.g., Wong et al. 2011 this collection).

GHMs are the first attempts to simulate the terrestrial water fluxes globally. They have a less detailed process representation compared to the LSMs, and generally use simple conceptual hydrological models to generate runoff. These often contain parameters calibrated on river flows; for example, Water-Global Analysis and Prognosis (WaterGAP; Alcamo et al. 2003) uses basin-specific parameters tuned on 11050 river basins and MacroProbability Distributed Model (MacroPDM; Arnell 1999) uses regional model parameters tuned to a range of river basins. These models include representations of hydrological stores and interventions, such as groundwater 
(Döll and Flörke 2005), irrigation (Döll and Siebert 2000), and water withdrawals and dams (Döll et al. 2009). GHMs also interface with global water use models to provide global estimates of water scarcity and stress (e.g., Alcamo et al. 2003, 2007).

All large-scale hydrological models need extensive gridded inputs of precipitation and driving climate variables for evaporation and snowmelt estimates. Within the European Union-funded WATCH project (http://www.euwatch.org), a comprehensive assessment of components of the water cycle, including large-scale hydrological extremes for the twentieth and twenty-first centuries, are being made using hydrological and land surface models. A number of global datasets are available [e.g., Sheffield et al. 2006; the Global Soil Wetness Project (GSWP); http://disc.sci.gsfc.nasa.gov/precipitation]. A new global subdaily meteorological forcing data has recently been produced [i.e., WATCH Forcing Data, (WFD)] for use with land surface and hydrological models (Weedon et al. 2011, this collection). This dataset uses the Climate Research Unit (CRU; Mitchell and Jones 2005) and Global Precipitation Climatology Centre (GPCC; Fuchs et al. 2007) to provide the mean climate and global reanalysis products to distribute the mean monthly climate to daily and hourly estimates. The WFD has improved on previously published meteorological forcing data, providing half-degree rather than one-degree resolution and covering the whole of the twentieth century (1901-2001). In addition, key differences in processing (Weedon et al. 2011, this collection) involved (i) the use of 40-yr European Centre for Medium-Range Weather Forecasts (ECMWF) Re-Analysis (ERA-40) data rather than National Center for Atmospheric Research-National Centers for Environmental Prediction (NCAR-NCEP), (ii) subdaily rainfall and snowfall rates are distinguished (rather than just providing total precipitation), and (iii) corrections have been applied for seasonal- and decadalscale variations in the effects of tropospheric and stratospheric aerosol loading on solar radiation (i.e., downward shortwave radiation), thereby accounting for the effects of "global dimming" and "brightening."

Thirteen land surface models and global hydrological models are currently participating in an international model intercomparison project [Water Model Intercomparison Project (WaterMIP); www.eu-watch.org/ watermip]. The objective of WaterMIP is to estimate current and potential future global water resources based on common forcing data (i.e., WFD) and a standardized simulation protocol (Haddeland et al. 2011, this collection). The models show a significant spread of the partitioning of precipitation into snowfall and rainfall and into evaporation and runoff. Simulated global evaporation over land shows a large range, from 415 to $586 \mathrm{~mm} \mathrm{yr}^{-1}$
(61 to $86 \times 10^{3} \mathrm{~km}^{3}$ ), and the simulated runoff ranges from 290 to $457 \mathrm{~mm} \mathrm{yr}^{-1}\left(43\right.$ to $\left.67 \times 10^{3} \mathrm{~km}^{3}\right)$-see Fig. 2 . The global mean model simulated runoff fraction (i.e., runoff coefficient) ranges from 0.33 to 0.52 . Models using a combined energy and water balance approach (LSMs) usually simulated lower runoff values compared to models only simulating the water balance (GHMs).

Prudhomme et al. (2011, this collection) and Corzo Perez et al. (2011) both show that LSMs and GHMs (driven by the WFD) can reproduce the dominant spatiotemporal variation of hydrological extremes. The basic characteristics of droughts and large-scale floods are captured, but the models struggle to reproduce local flood generation within the half-degree grid. This is also confirmed by Stahl et al. (2011, this collection), who found good agreement with observations for the medium-to-wet range for runoff from a high-resolution climate model, but the agreement dropped for the wettest anomaly (the lowest agreement was found for the dry anomalies).

\section{Future changes of the terrestrial water fluxes}

Changes in river flows, including hydrological extremes (floods and droughts) and water resources, are among the most important impacts of increasing greenhouse gases. Meehl et al. (2007) document the outputs from 23 climate models. All show an overall increase in rainfall but regionally there is less agreement; however, the majority (over $80 \%$ ) of models show an increase of rainfall in northern latitudes and a decrease in subtropical regions such as the Mediterranean. There is, however, still much work to be done to enable GCMs [and regional climate models (RegCMs)] to simulate the hydrological cycles consistently at basin and regional scales (see, e.g., Falloon et al. 2011, this collection, and Lucas-Picher et al. 2011, this collection). This is primarily due to the biases in the fields of precipitation and other weather data generated by the climate models and to the mismatch in spatial scales between the climate and hydrological models. Climate models tend to simulate a low number of dry days, which are compensated by too much drizzle, a bias in the mean, and the inability to reproduce the observed high-precipitation events (Boberg et al. 2009; Leander and Buishand 2007). For these reasons, hydrological models, which run offline, require bias-corrected and downscaled forcing data. Piani et al. (2010) have developed a statistical bias correction methodology for correcting climate model output to produce internally consistent fields that have the same statistical distribution of rainfall and temperature as in the observations. The bias correction, trained on late twentieth century daily rainfall and temperature, can then be applied to the 

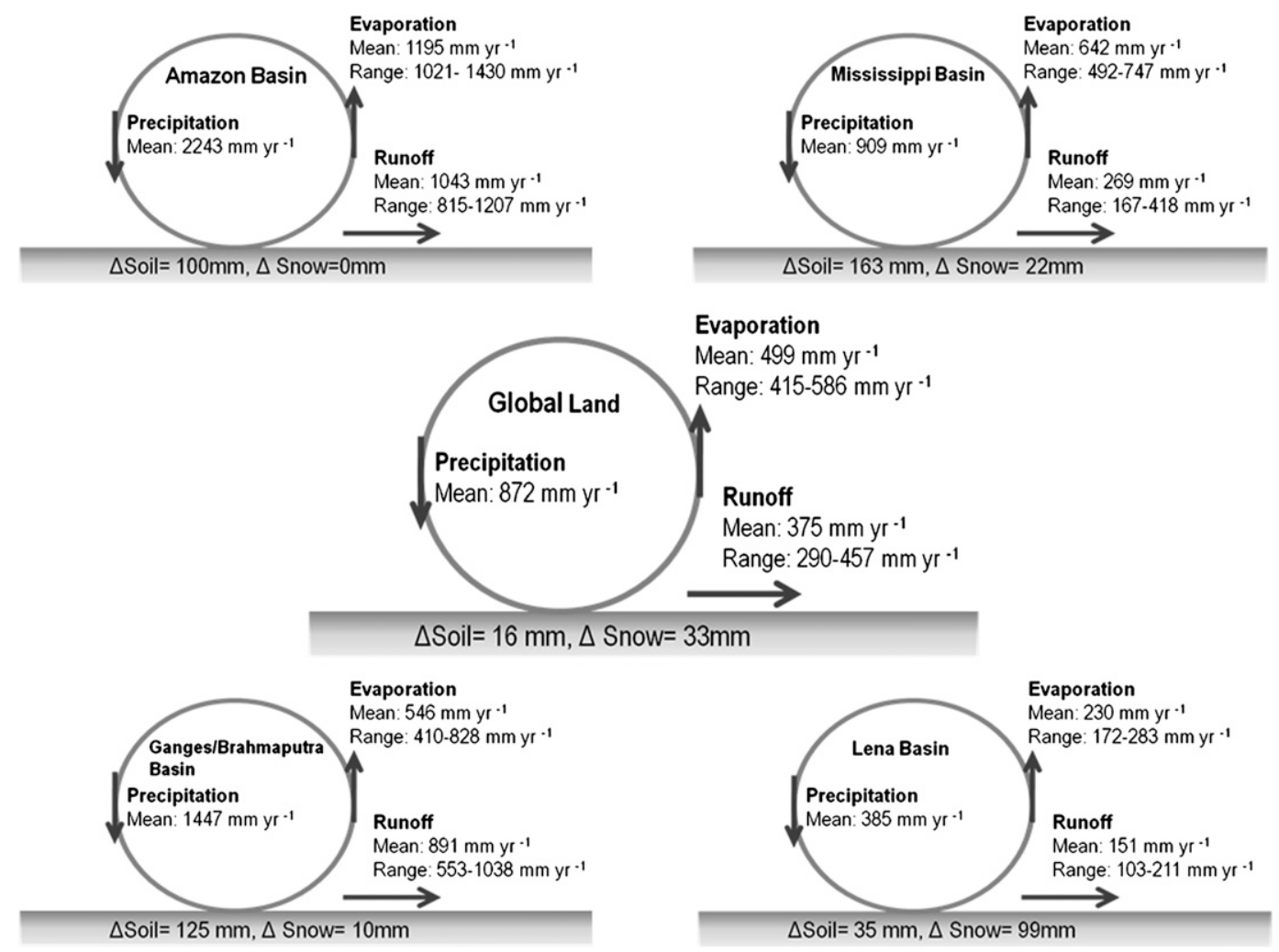

FIG. 2. Components of water fluxes and storages for global terrestrial land surface and four major basins representing different climate regimes (1985-99). The numbers represent simulation results of 11 models participating in WaterMIP (Haddeland et al. 2011).

output from twenty-first century climate simulations, thus preserving any change in the statistical properties of the rainfall and temperature time series predicted by the climate model. Hagemann et al. (2011, this collection) consider the impact of this bias correction on the projected climate change signals from three GCMs and conclude that the bias correction is of a similar order of magnitude as the uncertainty related to the choice of climate model or hydrology model.

Changes in the global water cycle as a result of climate change, land use change, and increased anthropogenic water use will have a large impact on global water resources (Ludwig and Moench 2009). In the coming decades the number and extent of water-scarce regions is likely to increase, mainly as a result of increased water demands (Gerten et al. 2011, this collection; Vörösmarty et al. 2000). However, the midlatitudes (e.g., the waterscare regions around the Mediterranean), are projected to be worse off in the future because of more severe droughts (Bates et al. 2008). In some regions, such as western and southern Australia and the Andes, climate change already has a profound impact on water resources (e.g., Barnett et al. 2005). Global change is not only affecting the amount of water available, but will also have an effect on water quality (e.g., Boxall et al. 2009). For example, the combination of higher atmospheric temperatures with lower summer discharge can have a profound impact on water temperatures (Van Vliet and Zwolsman 2008; ) and, in turn, stream ecology, with potential severe consequences for the energy sector (e.g., restriction on cooling water use). Food production (the primary use of water globally) is very likely to be impacted by the increasing scarcity of water. Biophysical models suggest a potential ameliorating increase in food production resulting from increased $\mathrm{CO}_{2}$ concentrations; however, such an increase may not be realized unless measures are taken to overcome nutrient limitations and pests in low-managed systems (Gerten et al. 2011, this collection).

\section{Uncertainty and challenges}

There are many uncertainties in our understanding of the current global water cycle and how it will develop in the future. The lack of agreement between climate 
models of the magnitude (and sign) of future regional precipitation change is well documented (e.g., Meehl et al. 2007). Also of concern is the difficulty climate models have in simulating current precipitation and circulation patterns (Palmer et al. 2008; Lucas-Picher et al. 2011, this collection). Added to these uncertainties is the range of responses of the offline hydrological models (Haddeland et al. 2011, this collection) commonly used for impact and adaptation studies. There is clearly an imperative to improve the regional simulations of precipitation and runoff. This is a longterm task that will be achieved through improving the parameterizations within the climate and hydrological models, including processes and feedbacks and particularly the anthropogenic influences on land cover and the hydrological cycle. An essential requirement will be improved regional and global datasets and the closer synthesis between data and models.

The WATCH project has aimed to provide a more consistent analysis of components of the terrestrial water cycle for the twentieth and twenty-first centuries. The project has produced new datasets to drive a range of global hydrological models, providing new tools (e.g., to bias correct existing climate model outputs) and new analyses of global and regional water resources, floods, and droughts. An important result is the better understanding of the uncertainties in the hydrological models used for impact analysis. We expect this understanding to lead to improved land surface and global hydrology models (and ultimately improved climate model simulations). However, it will be important in the future to present the uncertainty in hydrometeorological simulations, probably through ensembles of models, within analyses of climate impacts and adaptation.

The improvement of our simulations of regional precipitation will take many years, if not decades. In the meantime, the community needs to find ways of providing meaningful assessments of future water resources to policy makers and other stakeholders. This must include a realistic discussion of uncertainty and risk that does not swamp the key message that the hydrological cycle will change in the future under the combined pressures of changing climate and increasing demands of agriculture, industry, and water supply.

Acknowledgments. This preface was developed as part of the European Union (FP6)-funded integrated program called WATCH (Contract 036946). M.B. and G.P.W. were also supported by the Joint DECC and DEFRA Integrated Climate Programme-DECC/ DEFRA (GA011101).

\section{REFERENCES}

Abbott, M. B., J. C. Bathurst, J. A. Cunge, P. E. O'Connell, and J. Rasmussen, 1986: An introduction to the European Hydrological System-Systeme Hydrologique Europeen, "SHE", 1: History and philosophy of a physically-based, distributed modelling system. J. Hydrol., 87, 45-59.

Alcamo, J., P. Döll, T. Heinrichs, F. Kaspar, B. Lehner, T. Rösch, and S. Siebert, 2003: Development and testing of the WaterGAP 2 global model of water use and availability. Hydrol. Sci. J., 48, 317-333.

_ M. Florke, and M. Marker, 2007: Future long-term changes in global water resources driven by socioeconomic and climatic change. Hydrol. Sci. J., 52, 247-275.

Allen, M. R., and W. J. Ingram, 2002: Constraints on future changes in climate and the hydrologic cycle. Nature, 419, 224-232.

Arnell, N. W., 1999: A simple water balance model for the simulation of streamflow over a large geographic domain. J. Hydrol., 217, 314-335.

Barnett, T. P., J. C. Adam, and D. P. Lettenmaier, 2005: Potential impacts of a warming climate on water availability in snowdominated regions. Nature, 438, 303-309.

Bates, B. C., Z. W. Kundzewicz, S. Wu, and J. P. Palutikof, Eds., 2008: Climate change and water. IPCC Tech. Paper 6, 210 pp.

Beven, K. J., 2001: Rainfall-Runoff Modeling: The Primer. John Wiley, $372 \mathrm{pp}$.

, 2002: Towards an alternative blueprint for a physically based digitally simulated hydrologic response modelling system. Hydrol. Processes, 16, 189-206.

Biemans, H., R. W. A. Hutjes, P. Kabat, B. J. Strengers, D. Gerten, and S. Rost, 2009: Effects of precipitation uncertainty on discharge calculations for main river basins. J. Hydrometeor., 10, 1011-1025.

Blyth, E. M., 2001: Relative influence of vertical and horizontal processes in large-scale water and energy balance modelling. Soil-Vegetation-Atmosphere Transfer Schemes and Large-Scale Hydrological Models, IAHS Press, Vol. 270, 3-10.

Boberg, F., P. Berg, P. Thejll, W. J. Gutowski, and J. H. Christensen, 2009: Improved confidence in climate change projections of precipitation evaluated using daily statistics from the PRUDENCE ensemble. Climate Dyn., 32, 1097-1106, doi:10.1007/s00382-008-0446-y.

Boxall, A. B. A., and Coauthors, 2009: Impacts of climate change on indirect human exposure to pathogens and chemicals from agriculture. Environ. Health Perspect., 117, 508-514.

Burke, E. J., S. J. Brown, and N. Christidis, 2006: Modeling the recent evolution of global drought and projections for the twenty-first century with the Hadley Centre climate model. J. Hydrometeor., 7, 1113-1125.

Cess, R. D., and Coauthors, 1991: Interpretation of snow-climate feedback as produced by 17 general circulation models. Science, 253, 888-892, doi:10.1126/science.253.5022.888.

Claussen, M., 2004: The global climate. Vegetation, Water, Humans and the Climate, P. Kabat et al., Eds., Global Change-The IGBP Series, Vol. 24, Springer, 33-57.

Corzo Perez, G. A., M. H. J. van Huijgevoort, F. Voß, and H. A. J. van Lanen, 2011: On the spatio-temporal analysis of hydrological droughts from global hydrological models. Hydrol. Earth Syst. Sci. Discuss., 8, 619-652, doi:10.5194/hessd-8-619-2011.

Dai, A., 2010: Drought under global warming: A review. Wiley Interdiscip. Rev. Climate Change, 2, 45-65, doi:10.1002/wcc.81.

- K. E. Trenberth, and T. Qian, 2004: A global dataset of Palmer Drought Severity Index for 1870-2002: Relationship with soil 
moisture and effects of surface warming. J. Hydrometeor., $\mathbf{5}$, 1117-1130.

Döll, P., and S. Siebert, 2000: Global modeling of irrigation water requirements. Water Resour. Res., 38, 1037, doi:10.1029/ 2001WR000355.

—, and M. Flörke, 2005: Global-scale estimation of diffuse groundwater recharge. Frankfurt Hydrology Paper 03, 21 pp.

_ flow alterations due to water withdrawals and reservoirs. Hydrol. Earth Syst. Sci., 13, 2413-2432.

Falloon, P., and R. A. Betts, 2010: Climate impacts on European agriculture and water management in the context of adaptation and mitigation-The importance of an integrated approach. Sci. Total Environ., 408, 5667-5687.

- _ - A. Wiltshire, R. Dankers, C. Mathison, and D. McNeall, 2011: Validation of river flows in HadGEM1 and HadCM3 with the TRIP river flow model. J. Hydrometeor., in press.

Fischer, G., F. N. Tubiello, H. van Velthuizen, and D. A. Wiberg, 2007: Climate change impacts on irrigation water requirements: Effects of mitigation, 1990-2080. Technol. Forecasting Soc. Change, 74, 1083-1107.

Fuchs, T., U. Schneider, and B. Rudolf, 2007: Global precipitation analysis products of the GPCC. Deutscher Wetterdienst GPCC Rep., 12 pp.

Gedney, N., P. M. Cox, R. A. Betts, O. Boucher, C. Huntingford, and P. A. Stott, 2006: Detection of a direct carbon dioxide effect in continental river runoff records. Nature, 439, 835-838.

Gerten, D., and N. Gedney, 2008: Report on uncertainty in water budgets of the 20th century due to the representation of the impact of $\mathrm{CO}_{2}$ enrichment. WATCH Tech. Rep. 3, 7 pp. [Available online at http://www.eu-watch.org/publications/technicalreports.]

_ J. Heinke, H. Hoff, H. Biemans, M. Fader, and K. Waha, 2011: Global water availability and requirements for future food production. J. Hydrometeor., 12, 885-899.

Groisman, P. Y., R. W. Knight, D. R. Easterling, T. R. Karl, G. C. Hegerl, and V. N. Razuvaev, 2005: Trends in intense precipitation in the climate record. J. Climate, 18, 1326-1350.

Haddeland, I., and Coauthors, 2011: Multimodel estimate of the global water balance: Setup and first results. J. Hydrometeor., 12, 869-884.

Hagemann, S., C. Chen, J. O. Härter, J. Heinke, D. Gerten, and C. Piani, 2011: Impact of a statistical bias correction on the projected hydrological changes obtained from three GCMs and two hydrology models. J. Hydrometeor., 12, 556-578.

Held, I. M., and B. J. Soden, 2006: Robust responses of the hydrological cycle to global warming. J. Climate, 19, 5686-5699.

Huntington, T. G., 2006: Evidence for intensification of the global water cycle: Review and synthesis. J. Hydrol., 319, 83-95.

Jakeman, A., and G. M. Hornberger, 1993: How much complexity is warranted in a rainfall-runoff model? Water Resour. Res., 29, 2637-2649.

Jung, M., and Coauthors, 2010: Recent decline in the global land evapotranspiration trend due to limited moisture supply. $\mathrm{Na}$ ture, 467, 951-954.

Klein Tank, A. M. G., and G. P. Konnen, 2003: Trends in indices of daily temperature and precipitation extremes in Europe, 1946-99. J. Climate, 16, 3665-3680.

Leander, R., and T. A. Buishand, 2007: Resampling of regional climate model output for the simulation of extreme river flows. J. Hydrol., 332, 487-496.

Liang, X., D. P. Lettenmaier, E. F. Wood, and S. J. Burges, 1994: A simple hydrologically based model of land surface water and energy fluxes for general circulation models. J. Geophys. Res., 99 (D7), 14 415-14 428.

Lucas-Picher, P., and Coauthors, 2011: Can regional climate models represent the Indian monsoon? J. Hydrometeor., 12, 849-868.

Ludwig, F., and M. Moench, 2009: The impacts of climate change on water. Climate Change Adaptation in the Water Sector, F. Ludwig et al., Eds., Earthscan, 35-50.

McGuire, V. L., 2009: Water-level changes in the High Plains aquifer, predevelopment to 2007, 2005-06, and 2006-07. U.S. Geological Survey Scientific Investigations Rep. 2009-5019, 9 pp. [Available online at http://pubs.usgs.gov/sir/2009/5019/.]

Meehl, G. A., and Coauthors, 2007: Global climate projections. Climate Change 2007: The Physical Science Basis, S. Solomon et al., Eds., Cambridge University Press, 747-845.

Mitchell, T. D., and P. D. Jones, 2005: An improved method of constructing a database of monthly climate observations and associated high-resolution grids. Int. J. Climatol., 25, 693-712.

Moore, R. J., 2007: The PDM rainfall-runoff model. Hydrol. Earth Syst. Sci., 11, 483-499.

Pall, P., T. Aina, D. A. Stone, P. A. Stott, T. Nozawa, A. G. J. Hilberts, D. Lohmann, and M. R. Allen, 2011: Anthropogenic greenhouse gas contribution to flood risk in England and Wales in autumn 2011. Nature, 470, 382-383.

Palmer, T. N., F. J. Doblas-Reyes, A. Weisheimer, and M. J. Rodwell, 2008: Toward seamless prediction: Calibration of climate change projections using seasonal forecasts. Bull. Amer. Meteor. Soc., 89, 459-470.

Peterson, B. J., R. M. Holmes, J. W. McClelland, C. J. Vörösmarty, R. B. Lammers, A. I. Shiklomanov, I. A. Shiklomanov, and S. Rahmstorf, 2002: Increasing river discharge to the Arctic Ocean. Science, 298, 2171-2173.

Piani, C., J. O. Haerter, and E. Coppola, 2010: Statistical bias correction for daily precipitation in regional climate models over Europe. Theor. Appl. Climatol., 99, 187-192, doi:10.1007/ S00704-009-0134-9.

Prudhomme, C., S. Parry, J. Hannaford, D. B. Clark, S. Hagemann, and F. Voss, 2011: How well do large-scale models reproduce regional hydrological extremes in Europe? J. Hydrometeor., 12, 1181-1204.

Rodell, M., I. Velicogna, and J. S. Famiglietti, 2009: Satellite-based estimates of groundwater depletion in India. Nature, 460, 999 1002.

Roderick, M. L., and G. D. Farquhar, 2002: The cause of decreased pan evaporation over the past 50 years. Science, 298, 1410-1411.

- L. D. Rotstayne, G. D. Farquahar, and M. T. Hobbins, 2007: On the attribution of changing pan evaporation. Geophys. Res. Lett., 34, L17403, doi:10.1029/2007GL031166.

Sheffield, J., G. Goteti, and E. F. Wood, 2006: Development of a high-resolution global dataset of meteorological forcings for land surface modeling. J. Climate, 19, 3088-3111.

Stahl, K., and Coauthors, 2010: Streamflow trends in Europe: Evidence from a dataset of near-natural catchments. Hydrol. Earth Syst. Sci., 14, 2367-2382, doi:10.5194/hess-14-23672010.

, L. M. Tallaksen, L. Gudmundsson, and J. H. Christensen, 2011: Streamflow data from small basins: A challenging test to high-resolution regional climate modeling. J. Hydrometeor., 12, 900-912.

Strzepek, K., and B. Boehlert, 2010: Competition for water for the food system. Philos. Trans. Roy. Soc. London, B365, 2927-2940.

Trenberth, K. E., L. Smith, T. Qian, A. Dai, and J. Fasullo, 2007: Estimates of the global water budget and its annual cycle using observational and model data. J. Hydrometeor., 8, 758-769. 
Van Vliet, M. T. H., and J. J. G. Zwolsman, 2008: Impact of summer droughts on the water quality of the Meuse River. J. Hydrol., 353, 1-17.

Vörösmarty, C. J., P. Green, J. Salisbury, and R. B. Lammers, 2000: Global water resources: Vulnerability from climate change and population growth. Science, 289, 284-288.

— and river biodiversity. Nature, 467, 555-561.

Ward, P. J., K. M. Strzepek, W. Pieter Pauw, M. Luke, W. M. Brander, G. A. Hughes, and J. C. J. H. Aerts, 2010: Partial costs of global climate change adaptation for the supply of raw industrial and municipal water: A methodology and application. Environ. Res. Lett., 5, 044011, doi:10.1088/17489326/5/4/044011.

Weedon, G. P., and Coauthors, 2011: Creation of the WATCH Forcing Data and its use to assess global and regional reference crop evaporation over land during the twentieth century. J. Hydrometeor., 12, 823-848.
Wentz, F. J., L. Ricciardulli, K. Hilburn, and C. Mears, 2007: How much more rain will global warming bring? Science, 317, 233 235, doi:10.1126/science.1140746.

Wild, M., and Coauthors, 2005: From dimming to brightening: Decadal changes in solar radiation at Earth's surface. Science, 308, 847-850, doi:10.1126/science.1103215.

Wong, W. K., S. Beldring, T. Engen-Skaugem, I. Haddeland, and H. Hisdal, 2011: Climate change effects on spatiotemporal patterns of hydroclimatological summer droughts in Norway. J. Hydrometeor., 12, 1205-1220.

Zhang, X., F. W. Zwiers, G. C. Hegerl, F. H. Lambert, N. P. Gillett, S. Solomon, P. A. Stott, and T. Nozawa, 2007: Detection of human influence on twentieth-century precipitation trends. Nature, 448, 461-465.

Zolina, O., C. Simmer, S. K. Gulev, and S. Kollet, 2010: Changing structure of European precipitation: Longer wet periods leading to more abundant rainfalls. Geophys. Res. Lett., 37, L06704, doi:10.1029/2010GL042468. 